\title{
Characterization of crtRB1 Gene Polymorphism and $\beta$-Carotene Content in Maize Landraces Originated From North Eastern Himalayan Region (NEHR) of India
}

\section{OPEN ACCESS}

Edited by:

Abdul Wakeel,

University of Agriculture, Pakistan

Reviewed by:

Agnieszka Barbara Najda,

University of Life Sciences of

Lublin, Poland

Muhammad Ramzan Khan,

Quaid-i-Azam University, Pakistan

*Correspondence:

Senthil Natesan

senthil_natesan@tnau.ac.in

Specialty section:

This article was submitted to

Crop Biology and Sustainability,

a section of the journal

Frontiers in Sustainable Food Systems

Received: 05 February 2020

Accepted: 01 May 2020

Published: 12 June 2020

Citation:

Natesan S, Singh TS, Duraisamy T, Chandrasekharan N, Chandran S, Adhimoolam K, Muniyandi SJ,

Sampathrajan V, Kalipatty

Nalliappan G, Muthurajan R and Meitei LJ (2020) Characterization of crtRB1 Gene Polymorphism and

$\beta$-Carotene Content in Maize

Landraces Originated From North Eastern Himalayan Region (NEHR) of India. Front. Sustain. Food Syst. 4:78. doi: 10.3389/fsufs.2020.00078

\begin{abstract}
Senthil Natesan ${ }^{1 *}$, Thangjam Surchandra Singh ${ }^{2}$, Thirusenduraselvi Duraisamy ${ }^{3}$, Neelima Chandrasekharan ${ }^{4}$, Sarankumar Chandran ${ }^{1}$, Karthikeyan Adhimoolam ${ }^{5}$, Samuel Jeberson Muniyandi ${ }^{6}$, Vellaikumar Sampathrajan ${ }^{7}$, Ganesan Kalipatty Nalliappan ${ }^{8}$, Raveendran Muthurajan ${ }^{4}$ and Laishram Joykumar Meitei ${ }^{9}$
\end{abstract}

\begin{abstract}
${ }^{1}$ Department of Plant Molecular Biology and Bioinformatics, Centre for Plant Molecular Biology and Biotechnology, Tamil Nadu Agricultural University, Coimbatore, India, ${ }^{2}$ ICAR Research Complex for NEH Region, Imphal, India, ${ }^{3}$ Department of Seed Science and Technology, Tamil Nadu Agricultural University, Coimbatore, India, ${ }^{4}$ Department of Plant Biotechnology, Centre for Plant Molecular Biology and Biotechnology, Tamil Nadu Agricultural University, Coimbatore, India, ${ }^{5}$ Subtropical Horticulture Research Institute, Jeju National University, Jeju, South Korea, ${ }^{6}$ AICRP-MULLARP, Directorate of Research, Central Agricultural University, Imphal, India, ${ }^{7}$ Department of Biotechnology, Agricultural College and Research Institute, Tamil Nadu Agricultural University, Madurai, India, ${ }^{8}$ Department of Plant Breeding and Genetics, Centre for Plant Breeding and Genetics, Tamil Nadu Agricultural University, Coimbatore, India, ${ }^{9}$ Department of Plant Breeding and Genetics, Central Agricultural University, Imphal, India
\end{abstract}

Micronutrient malnutrition or hidden hunger affects a large population in developing and developed countries. One of the major micronutrient deficiencies is vitamin A, which causes several major disorders such as growth retardation, blindness, and increased susceptibility to infectious disease. Maize has been shown for great natural variation for provitamin A carotenoids and it is a promising crop for provitamin A biofortification. crtRB1 ( $\beta$-carotene hydroxylase 1) gene is responsible for enhancing $\beta$-carotene content in maize. DNA marker linked to the crtRB1 gene had a considerable effect on enhancing $\beta$-carotene content that has been identified previously. In India, the North-East Himalayan region (NEHR) is the center of maize diversity, maize landraces from this area have good agronomic characters and well-adapted to stress environments. However, no prior knowledge about the existence of the crtRB1 gene and that of the $\beta$-carotene content in NEHR maize landraces is available. Hence, the goal of this study was to characterize the crtRB1 gene polymorphism and $\beta$-carotene content in NEHR maize landraces using gene-specific marker (crtRB1 3'TE) and high-performance liquid chromatography (HPLC). We screened 26 maize landraces using crtRB1 3'TE marker and found that all the maize landraces to be either homozygous to the unfavorable allele or heterozygous (both favorable and unfavorable alleles) but no landraces were homozygous for favorable allele. On the other hand, HPLC analysis showed that the $\beta$-carotene content in the heterozygous allele type of landraces varied from 1.36 to $4.40 \mu \mathrm{g} / \mathrm{g}$ while unfavorable homozygous allele type landraces varied from 0.33 to $0.94 \mu \mathrm{g} / \mathrm{g}$. It was found that the landraces CAU-M66 and CAU-M16 possess the highest amount of $\beta$-carotene content $(4.40$ and $4.26 \mu \mathrm{g} / \mathrm{g})$ and had the crtRB1 favorable allele in heterozygous condition 
among the 26 maize landraces studied. This is the first study that disclosed the crtRB1 gene polymorphism and the $\beta$-carotene content in NEHR maize landraces. The newly identified $\beta$-carotene-rich maize landraces can be effectively utilized in the breeding programs to enhance the $\beta$-carotene content in maize.

Keywords: maize, $\beta$-carotene, crtRB1, North-East Himalayan Region, vitamin A

\section{INTRODUCTION}

Maize (Zea mays) is one of the primary cereals in the world and a major contributor to food security in Asia, Africa, and Latin America. It can also be grown in a variety of agro-climatic zones and has the potential to be bred to offer productive cultivars that are attractive to farmers, and consumers, in particular for their nutritional properties (Pingali, 2001). Micronutrient malnutrition or hidden hunger is affecting a large population in developing and developed countries. In particular, Vitamin A deficiency causes serious health issues such as growth retardation, blindness, and increased susceptibility to infectious disease to children and pregnant women (Dary et al., 2002; West, 2003). Maize possesses great natural variation for provitamin A carotenoids, thus maize has been targeted for provitamin A biofortification (Pillay et al., 2014). HarvestPlus has combined with CIMMYT and other partner institutions to develop maize varieties that are high yielding, profitable, suitable to consumers, and also rich in Provitamin A carotenoids comprising of $\alpha$-carotene, $\beta$-carotene, and $\beta$-cryptoxanthin, which can be metabolically converted to active vitamin A substances in the human body (Bouis and Welch, 2010; Asson-Batres and Rochette-Egly, 2016). So far, the enhancement of Provitamin A is mostly focused on the selection of $\beta$-carotene content. Two genes namely, crtRB1 ( $\beta$-carotene hydroxylase 1$)$, and LcyE (lycopene epsilon cyclase) had a considerable effect on enhancing $\beta$-carotene content in maize (Harjes et al., 2008; Yan et al., 2010). $\beta$-carotene is hydroxylated to $\beta$ cryptoxanthin by the $\operatorname{crtRB1}$ gene and was found to be more effective in increasing the $\beta$-carotene content than the $L c y E$ (Babu et al., 2013). The $c r t R B 1$ gene is present in three allelic forms due to the $\operatorname{crtRB}-3$ 'TE polymorphism that exists within the gene. Allele 1 (543 bp; with-out TE insertion), is identified as a favorable allele for increasing the $\beta$-carotene by decreasing transcript expression of the crtRB1 gene, while allele $2(296+875 \mathrm{bp}$; with 325 bp TE insertion), and allele $3(296+1,221+1,880 \mathrm{bp}$; with $1,250 \mathrm{bp}$ TE insertion) cause unfavorable effects (Yan et al., 2010). Polymerase chain reaction (PCR)-based co-dominant markers were identified based on these polymorphisms, and these markers useful to enhance the $\beta$-carotene content by marker-assisted selection (MAS). Many studies confirmed that $c r t R B 1-3^{\prime}$ TE polymorphism is associated with effecting a 2 - to 10 -fold increase in $\beta$-carotene content in maize kernels (Muthusamy et al., 2014; Zunjare et al., 2018; Chandran et al., 2019).

Maize is the principal crop ensuring food security, after rice, cultivated in the North-East Himalayan Region (NEHR) of India. Besides, NEHR is the center of maize diversity in India and maize landraces from this area have good agronomic characters and well-adapted to stress environments. Thus, they are still conserved and exploited by NEHR farmers for various purposes. Tremendous phenotypic diversity and a large variation in kernel color (i.e., white, violet-brown, yellow, orange-yellow, light-red, dark red, brown-black) were observed in the maize landraces of NEHR. CAU-M16 (Kabullamah), also known as finger maize is popular for its aromatic taste with small size cob. Whereas, CAUM66 (Chujak) is known for its long cob and large round seeds as well as sweet taste. CAU-M60 (Vekla) is a medium-size cob originated from Ukhrul. However, no information is available about the presence of the $\operatorname{crtRB1}$ gene and the variation of $\beta$ carotene content in these landraces. Thus, the objective of this study was to characterize the $\operatorname{crtRB1}$ gene polymorphism and determine the $\beta$-carotene content variations in maize landraces originated in NEHR of India.

\section{MATERIALS AND METHODS}

\section{Plant Genetic Materials and Experimental Plot}

A total of 26 maize landraces from NEHR of India showing variations in kernel color (i.e., white, violet brown, yellow, orange-yellow, light red, dark red, brown-black etc.) were collected from farmer's field and used for this study (Figure 1, Table 1). Seeds of these landraces were available at the Central Agricultural University, Imphal, India. Twenty-six maize landraces were planted in a randomized complete block design (RCBD) with three replications at experimental farm, Central Agricultural University, Each landrace was planted in two rows ( $3 \mathrm{~m}$ length) at the spacing of 60 and $30 \mathrm{~cm}$ between rows and plants, respectively. Recommended agronomic practices were followed and each entry was carefully self-pollinated to avoid any possible contamination. Ears from each entry were harvested separately from individual plants representing three biological replicates and seeds were shelled and stored in dark conditions at $40^{\circ} \mathrm{C}$ until carotenoid extraction.

\section{Genomic DNA Isolation and PCR Analysis}

The genomic DNA was isolated from 3-week old seedlings using the cetyl trimethyl ammonium bromide (CTAB) method (Murray and Thompson, 1980). The isolated DNA was tested for its quality and quantity on a $0.8 \%$ agarose gel. The $c r t R B 1$ genespecific marker "crtRB1" (65F: ACACCACATGGACAAGTTCG, 62R: ACACTCTGGCCCATGAACAC, 66R: ACAGCAATACAG GGGACCAG) was used to identify the allelic variation of the crtRB1 gene. The polymerase chain reaction (PCR) was carried out in $10 \mu \mathrm{l}$ reaction containing $25 \mathrm{ng} / \mu \mathrm{l}$ of maize genomic DNA, $2 \mathrm{mM} \mathrm{MgCl}_{2}, 1 \mathrm{mM}$ dNTPs, $2 \mu \mathrm{M}$ of each primer, and $1.5 \mathrm{U}$ if Taq polymerase. After an initial denaturation for $5 \mathrm{~min}$ 


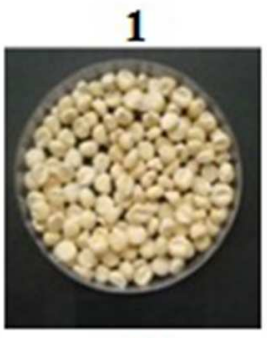

5

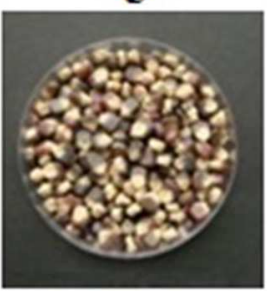

9

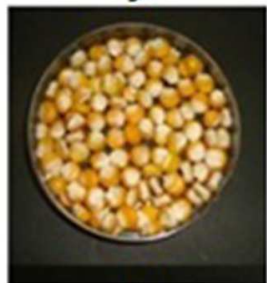

13

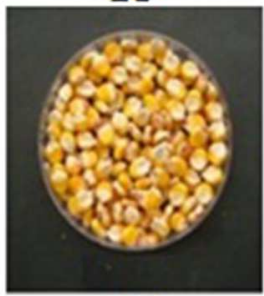

17

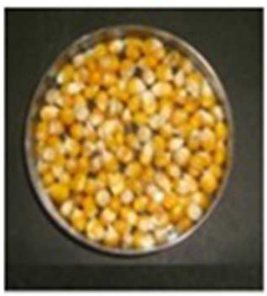

2

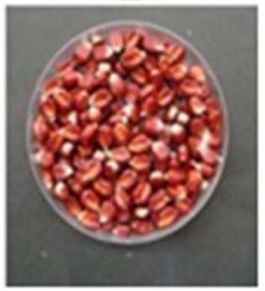

6

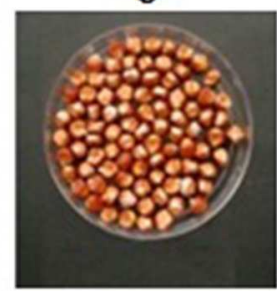

10

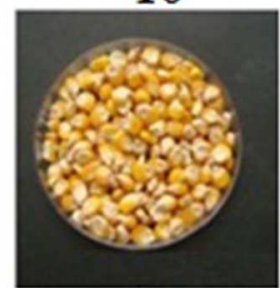

14

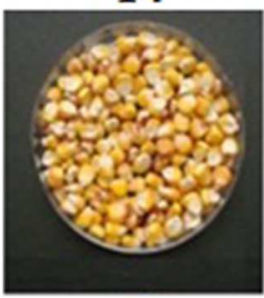

18

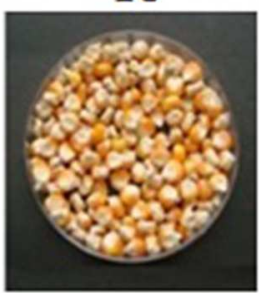

3

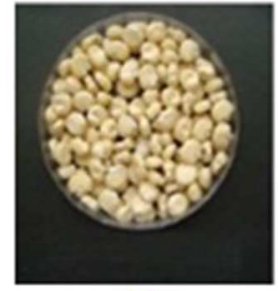

7

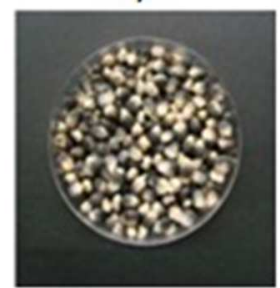

11

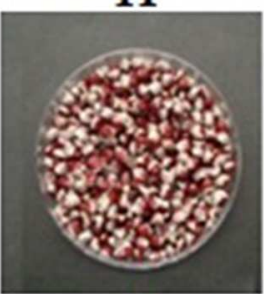

15
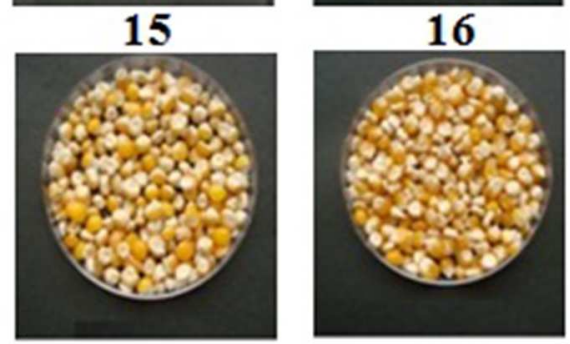

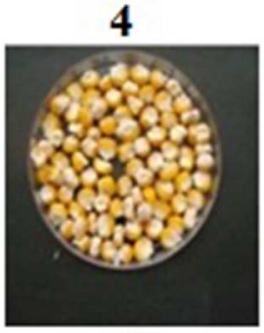

8

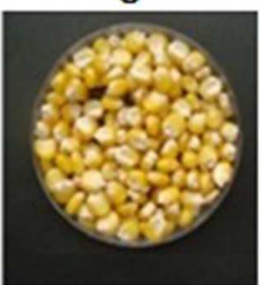

12

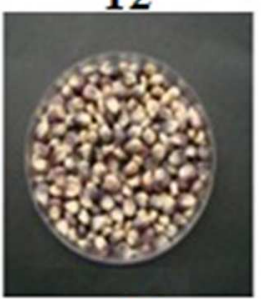

16

FIGURE 1 | Kernel color variation in NEH maize landraces. (1) CAU-M 1, (2) CAU-M 3, (3) CAU-M 5, (4) CAU-M 12, (5) CAU-M 13, (6) CAU-M 16, (7) CAU-M 19, (8) CAU-M 20, (9) CAU-M 24, (10) CAU-M 26, (11) CAU-M 27, (12) CAU-M 28, (13) CAU-M 31, (14) CAU-M 36, (15) CAU-M 52, (16) CAU-M 53, (17) CAU-M 60, (18) CAU-M 66.

at $94^{\circ} \mathrm{C}$ each cycle then comprised of denaturation at $94^{\circ} \mathrm{C}$ for $30 \mathrm{~s}$, annealing from 54 to $62^{\circ} \mathrm{C}$ for $30 \mathrm{~s}$ with a reduction of $0.5^{\circ} \mathrm{C}$ in each cycle, extension at $72^{\circ} \mathrm{C}$ for $45 \mathrm{~s}$ and was repeated for 19 cycles. This was followed by a denaturation for $30 \mathrm{~s}$ at $94^{\circ} \mathrm{C}$, annealing for $30 \mathrm{~s}$ at $60^{\circ} \mathrm{C}$, extension for $45 \mathrm{~s}$ at $72^{\circ} \mathrm{C}$ and a final extension of $72^{\circ} \mathrm{C}$ for $10 \mathrm{~min}$ at the end of 20 cycles. The PCR products were then mixed with bromophenol blue and loaded onto a $3 \%$ agarose gel and resolved for $3 \mathrm{~h}$ and visualized using a gel documentation system (Bio-Rad Laboratories Inc., USA).

\section{Estimation of Total Carotenoids and $\beta$-Carotene Contents}

Seeds samples were ground well to fine powder and extraction steps were undertaken in dark condition. The carotenoid was extracted as described by the Harvestplus protocol (RodriguezAmaya and Kimura, 2004). Quantification of the $\beta$-carotene was done using high-performance liquid chromatography (HPLC) system and samples were eluted through the Shimadzu HPLC Analytical C18G 120A column $(250 \times 4.6 \mathrm{~mm})$ and detected with 
TABLE 1 | Details of crtRB1 allele, total carotenoids, and $\beta$-carotene contents in maize landraces from NEHR of India.

\begin{tabular}{|c|c|c|c|c|c|c|c|c|}
\hline S.No & Gene bank No. & Code $^{1}$ & Local name & Place of cultivation & Kernel color and type & $\begin{array}{c}\text { crtRB1 } \\
\text { allele (bp) }\end{array}$ & $\begin{array}{c}\text { Total } \\
\text { carotenoids } \\
(\mu \mathrm{g} / \mathrm{g})\end{array}$ & $\begin{array}{c}\beta \text {-carotene } \\
(\mu \mathrm{g} / \mathrm{g})\end{array}$ \\
\hline 1 & PBG1107005 & CAU-M 12 & Minaya & Mizoram & Orange yellow & $296+543$ & 8.34 & 1.88 \\
\hline 2 & PBG1106006 & CAU-M 13 & Maime & Tripura & Yellow & $296+543$ & 5.57 & 1.38 \\
\hline 3 & PBG1107007 & CAU-M 16 & Kabullamah & Tamenglong-Manipur & Light red with yellow cap & $296+543$ & 6.88 & 4.26 \\
\hline 4 & PBG1107008 & CAU-M 17 & Mogadam & Tripura & Light red with yellow cap & $296+543$ & 2.18 & 1.36 \\
\hline 5 & PBG1107010 & CAU-M 19 & MogadamPaito & Tripura & Brown black & $296+543$ & 7.16 & 1.58 \\
\hline 6 & PBG1208027 & CAU-M 60 & Vekla & Manipur-Ukhrul & Orange yellow & $296+543$ & 32.53 & 3.80 \\
\hline 7 & PBG1108028 & CAU-M 66 & Chujak & Manipur-Yairipok & Orange yellow & $296+543$ & 36.37 & $4.40^{\star}$ \\
\hline 8 & PBG1108018 & CAU-M 28 & Makkai & Tripura & Violet brown & $296+543$ & 7.04 & 2.16 \\
\hline 9 & PBG1109024 & CAU-M 53 & $\begin{array}{l}\text { Chujak } \\
\text { (kabokpokpi) }\end{array}$ & Manipur-Serou & Orange yellow & $296+543$ & 16.21 & 0.74 \\
\hline 10 & PBG 1404028 & CAU M 138 & Makei & Sikkim collection & White & $296+543$ & 5.55 & 0.20 \\
\hline 11 & PBG1107009 & CAU-M 18 & Khamathei & Ukhrul-Manipur & Pale yellow & 296 & 14.39 & 0.64 \\
\hline 12 & PBG1107012 & CAU-M 20 & MakkaiPepe & Arunachal Pradesh & Orange yellow & 296 & 21.4 & 0.58 \\
\hline 13 & PBG1106001 & CAU-M 1 & Meraku & Meghalaya & White & 296 & 3.56 & 0.36 \\
\hline 14 & PBG1108016 & CAU-M 26 & Sohru(Seem) & Meghalaya & Orange yellow & 296 & 17.64 & 0.84 \\
\hline 15 & PBG1107013 & CAU-M 21 & Ambo & Tripura & Orange yellow & 296 & 3.74 & 0.71 \\
\hline 16 & PBG1110026 & CAU-M 55 & Thangkutta & $\begin{array}{l}\text { Manipur-Toupokpi, } \\
\text { Chandel }\end{array}$ & Orange yellow & 296 & 20.00 & 0.94 \\
\hline 17 & PBG1108020 & CAU-M 31 & Kolbu & Manipur-Curchandpur & Orange yellow & 296 & 8.37 & 0.82 \\
\hline 18 & PBG1108022 & CAU-M 39 & Chujak & Ukhrul-Manipur & Violet brown & 296 & 6.24 & 0.38 \\
\hline 19 & PBG1108015 & CAU-M 25 & Khamathei & Ukhrul-Manipur & Orange yellow & 296 & 16.58 & 0.67 \\
\hline 20 & PBG1106002 & CAU-M 2 & Chujak & Andro-Manipur & Yellow & 296 & 5.32 & 0.83 \\
\hline 21 & PBG1106003 & CAU-M 3 & Chujak & Khurai-Manipur & Dark red with yellow cap & 296 & 8.12 & 1.57 \\
\hline 22 & PBG11060023 & CAU-M 52 & Block chujak & Serou-Manipur & Yellow orange & 296 & 25.39 & 0.43 \\
\hline 23 & PBG1108022 & CAU M 36 & Kolbu & Churchandpur-Manipur & White/cream & 296 & 21.76 & 0.86 \\
\hline 24 & PBG1107014 & CAU M 24 & Muralimakai & Sikkim & Orange yellow & 296 & 17.97 & 3.5 \\
\hline 25 & PBG 1109029 & CAU-M 65 & Mogadham & Khowai-Tripura & white & 296 & 4.26 & 1.48 \\
\hline 26 & PBG1108017 & CAU-M 27 & Ambo & Ukhrul-Manipur & Dark red & 296 & 1.44 & 0.33 \\
\hline
\end{tabular}

SEd value: 0.02, $C D$ value $(p=0.05): 0.03, C D$ value $(p=0.01): 0.04$. ${ }^{\star}$ Significantly superior when compared to the other landraces at both 5 and $1 \%$.

a photodiode array detector set at $450 \mathrm{~nm}$. The mobile phase comprising of Acetonitrile: Methanol: Ethyl acetate (80:10:10) at high pressure through the column, and the flow rate was $1 \mathrm{ml} \mathrm{min}{ }^{-1}$. Standards for $\beta$-carotene from M/s. Sigma Aldrich India was reconstituted in acetone to five different concentrations $(0.1 ; 1 ; 10 ; 50 ; 100 \mu \mathrm{g} / \mathrm{g}$; Kurilich and Juvik, 1999) and was used to construct the standard curve for $\beta$-carotene. The $\beta$ carotene content in each landrace was measured using standard regression with external standards. The amount of $\beta$-carotene was calculated by comparing the chromatogram to that of the standard. The $\beta$-carotene content of the 26 landraces were analyzed using Analysis of Variance (ANOVA). The SEd and $\mathrm{CD}$ values were also calculated at both 5 and $1 \%$ to select for the superior landrace that has significantly higher content of $\beta$-carotene.

\section{RESULTS AND DISCUSSION}

Maize landraces are one of the major sources for breeding programs due to their unique characteristics and ability to adapt to various stress environments. Mexican landraces "Tuxpeño" exhibits early maturity, drought-tolerance, and resistance to tropical foliar diseases, and better stalk strength (GutiérrezRodríguez et al., 1998). "Bolita" exhibits drought tolerance and better tortilla-making properties; "Olotillo" exhibits strong performance on poor or unfertilized soils (Benz, 1987). In India, genotypes well-adapted to the hill region and hybrids highlytolerant to leaf blight were developed using landraces originated from Jammu \& Kashmir and Uttarakhand (Prasanna, 2010). NEHR is the center of maize diversity in India. Maize landraces from NEHR possess many valuable agronomic traits. Despite its agronomic benefits, it has remained as an underutilized. In the past decades, only limited attempts have been done to study the features of NEHR maize landraces. Efforts on phenotypic and molecular characterization of a set of 48 maize landrace accessions being made (Sharma et al., 2010). But, studies attempted to characterize the $\operatorname{crtRB1}$ gene polymorphism and the $\beta$-carotene content in the landraces of India are comparatively meager. In particular, no studies have been reported from NEHR maize landraces. 


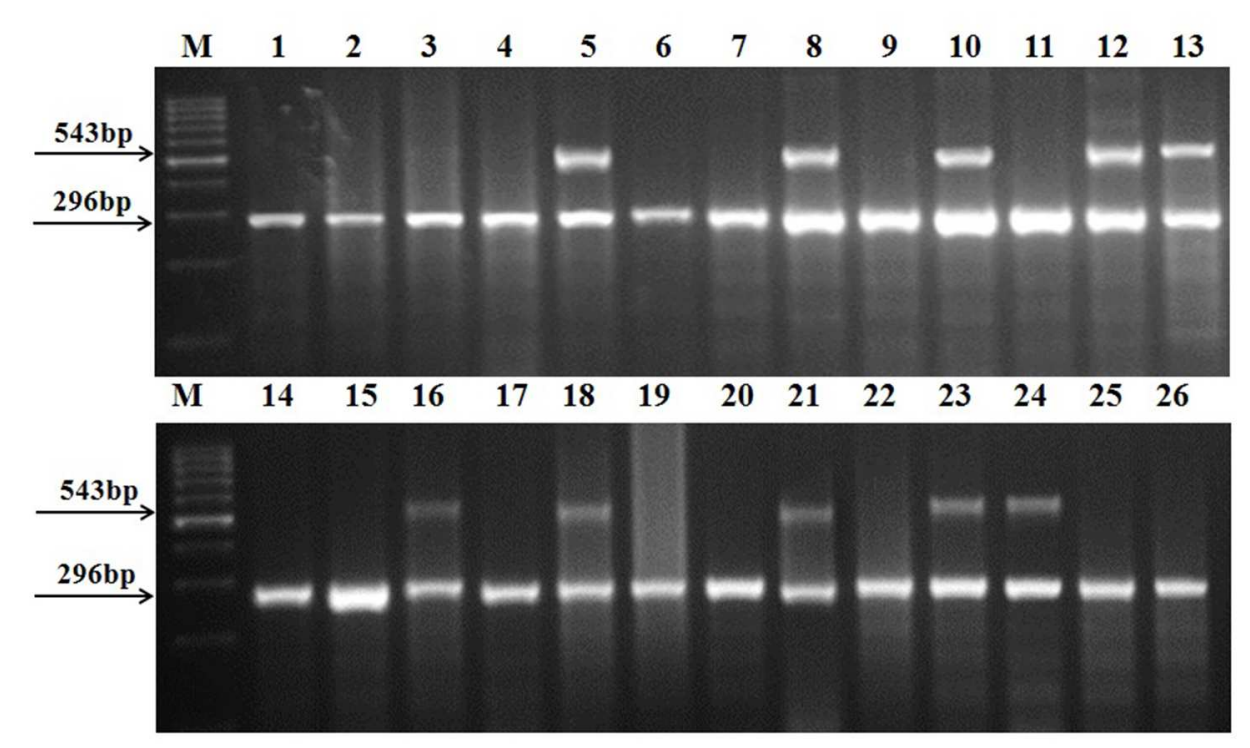

FIGURE 2 | Screening maize landraces from NEHR of India using crtRB1 gene specific marker. (M) Marker (100 bp), (1) CAU-M 18, (2) CAU-M 20, (3), CAU-M 1, (4) CAU-M 26, (5) CAU-M 12, (6) CAU-M 21, (7) CAU-M 55, (8) CAU-M 13, (9) CAU-M 31, (10) CAU-M 16, (11) CAU-M 39, (12) CAU-M 17, (13) CAU-M 19, (14) CAU-M 25, (15) CAU-M 2, (16) CAU-M 60, (17) CAU-M 3, (18) CAU-M 66, (19) CAU-M 52, (20) CAU M 36, (21) CAU-M 28, (22) CAU M 24, (23) CAU-M 53, (24) CAU M 138, (25) CAU-M 65, (26) CAU-M 27.

MAS was a successful approach that can be used for the rapid selection of the target gene indirectly using molecular markers closely linked to a target gene (Ragot and Lee, 2007; Prasanna et al., 2010). crtRB1 had a significant effect on enhancing $\beta$ carotene content and it exists in three allelic forms Allele 1 (favorable effect), Allele 2, and Allele 3 (unfavorable effect) because of the crtRB-3'TE polymorphism that occurs within the gene (Yan et al., 2010). Co-dominant marker developed from the $3^{\prime} \mathrm{TE}$ region of the $\mathrm{cr} R B \mathrm{~B}$ gene facilitated the chance for accelerating the $\beta$-carotene improvement programs by MAS (Yan et al., 2010). Recently, many researchers used this allelebased marker to detect the $\operatorname{crtRB1}$ gene polymorphism in maize germplasms (Muthusamy et al., 2014; Zunjare et al., 2018; Chandran et al., 2019). In the present study, 26 maize landraces from NEHR were characterized for crtRB1 gene polymorphism using a gene-specific marker ( $\left.c r t R B 13^{\prime} \mathrm{TE}\right)$. It showed that none of the maize landraces were homozygous for the favorable allele (543 bp amplicon only), however, the landraces are either heterozygous [both favorable and unfavorable alleles $(296+$ 543 bp amplicons)] or homozygous [unfavorable allele (296 bp amplicon only)]. Ten maize landraces were found to contain the $\operatorname{crtRB} 1$ gene in the heterozygous form while the remaining 16 landraces were in homozygous form with the unfavorable allele (Figure 2). These results are consistent with the reports of Vignesh et al. (2012), Babu et al. (2013), Selvi et al. (2014), who described that the most favorable $\operatorname{crtRB1}$ allele is rare in frequency.

Further, we estimated the total carotenoid and $\beta$-carotene content in 26 maize landraces. The total carotenoid content in the 26 maize landraces ranged from 1.44 to $36.37(\mu \mathrm{g} / \mathrm{g})$ showing the diversity among the landraces. CAU-M66 was found to have a high total carotenoid content of $36.37 \%$ followed by CAU-M60 at $32.53 \%$. On the other hand, the $\beta$-carotene content varied from 1.36 to $4.40(\mu \mathrm{g} / \mathrm{g})$ in the heterozygous allele type landraces and 0.33 to $0.94(\mu \mathrm{g} / \mathrm{g})$ in the homozygous unfavorable allele type landraces. CAU-M66 (4.40 $\mu \mathrm{g} / \mathrm{g})$ and CAU-M16 $(4.26 \mu \mathrm{g} / \mathrm{g})$ exhibited the highest $\beta$-carotene content among the 26 landraces (Table 1). Similarly, Vignesh et al. (2012) revealed that the $\beta$ carotene content ranged from 0.02 to $16.50 \mu \mathrm{g} / \mathrm{g}$ in 105 maize inbreds. Selvi et al. (2014) reported that the $\beta$-carotene content of the maize inbreds varied from 0.23 to $7.92(\mu \mathrm{g} / \mathrm{g})$. Muthusamy et al. (2015) also reported that kernel $\beta$-carotene ranged from 0.41 to $11.51 \mu \mathrm{g} / \mathrm{g}$ in 14 yellow maize inbreds. Besides, our results also confirmed that the existence of the $\operatorname{crtRB1}$ favorable allele has a positive correlation with higher $\beta$-carotene content. However, Babu et al. (2013) reported that the favorable crtRB1 allele was found to be more efficient in accumulating higher $\beta$-carotene when present in homozygous condition than under heterozygous condition. Thus, in the near future, two maize landraces CAUM66 and CAU-M16 possess the highest amount of $\beta$-carotene content can be selfed for obtaining the homozygous favorable allele and also used as a starting material for the development of new maize varieties rich in $\beta$-carotene.

\section{CONCLUSION}

This is the first study report the crtRB1 gene polymorphism and $\beta$-carotene content variations in maize landraces originated from NEHR of India. Our study found that two maize land races CAU-M66 and CAU-M16 have the highest amount of $\beta$ carotene content and had the favorable allele in the heterozygous condition among the 26 maize landraces studied. These two 
maize landraces are a potential donors that can be exploited in $\beta$-carotene biofortification breeding.

\section{DATA AVAILABILITY STATEMENT}

The datasets generated for this study are available on request to the corresponding author.

\section{AUTHOR CONTRIBUTIONS}

SN, GK, and LM designed the methods and experiments. SM and RM provided suggestions on experiments and monitored the

\section{REFERENCES}

Asson-Batres, M. A., and Rochette-Egly, C. (2016). “The biochemistry of retinoid signaling II," in The Physiology of Vitamin A-Uptake, Transport, Metabolism and Signaling, eds. A. Batres, M. Ann, and R. Egly (Berlin: Springer), 9-10.

Babu, R., Rojas, N. P., Gao, S., Yan, J., and Pixley, K. (2013). Validation of the effects of molecular marker polymorphisms in LcyE and CrtRB1 on provitamin A concentrations for 26 tropical maize populations. Theor. Appl. Genet. 126, 389-399. doi: 10.1007/s00122-012-1987-3

Benz, B. F. (1987). Racial systematics and the evolution of Mexican maize. BAR. Int. 349, 121-136.

Bouis, H. E., and Welch, R. M. (2010). Biofortification-a sustainable agricultural strategy for reducing micronutrient malnutrition in the global south. Crop Sci. 50(Suppl. 1), S-20-S-32. doi: 10.2135/cropsci2009.09.0531

Chandran, S., Pukalenthy, B., Adhimoolam, K., Manickam, D., Sampathrajan, V., Chocklingam, V., et al. (2019). Marker-assisted selection to pyramid the opaque-2 (O2) and $\beta$-carotene (crtRB1) genes in maize. Front. Genet. 10:859. doi: 10.3389/fgene.2019.00859

Dary, O., Mora, J. O., and International Vitamin, A. C. G. (2002). Food fortification to reduce vitamin A deficiency: international Vitamin A consultative group recommendations. J. Nutr. 132(9 Suppl.), 2927S-2933S. doi: $10.1093 / \mathrm{jn} / 132.9 .2927 \mathrm{~S}$

Gutiérrez-Rodríguez, M., Miguel-Chavez, R. S., and Larque-Saavedra, A. (1998). Physiological aspects in tuxpeno maize with improved drought tolerance. Maydica 43, 137-141.

Harjes, C. E., Rocheford, T. R., Bai, L., Brutnell, T. P., Kandianis, C. B., Sowinski, S. G., et al. (2008). Natural genetic variation in lycopene epsilon cyclase tapped for maize biofortification. Science 319, 330-333. doi: 10.1126/science.1150255

Kurilich, A. C., and Juvik, J. A. (1999). Quantification of carotenoid and tocopherol antioxidants in zea mays. J. Agric. Food Chem. 47, 1948-1955. doi: $10.1021 /$ jf $981029 \mathrm{~d}$

Murray, M. G., and Thompson, W. F. (1980). Rapid isolation of high molecular weight plant DNA. Nucleic Acids Res. 8, 4321-4325. doi: 10.1093/nar/8.1 9.4321

Muthusamy, V., Hossain, F., Thirunavukkarasu, N., Choudhary, M., Saha, S., Bhat, J. S., et al. (2014). Development of $\beta$-carotene rich maize hybrids through marker-assisted introgression of $\beta$-carotene hydroxylase allele. PLoS ONE 9:e113583. doi: 10.1371/journal.pone. 0113583

Muthusamy, V., Hossain, F., Thirunavukkarasu, N., Saha, S., and Gupta, H. S. (2015). Allelic variations for lycopene- $\varepsilon-c y c l a s e, ~ a n d$, $\beta$-carotene hydroxylase genes in maize inbreds and their utilization in $\beta$-carotene enrichment programme. Cogent. Food Agri. 1:1033141. doi: 10.1080/23311932.2015.1033141

Pillay, K., Siwela, M., Derera, J., and Veldman, F. J. (2014). Provitamin A carotenoids in biofortified maize and their retention during processing and preparation of South African maize foods. J. Food Sci. Technol. 51, 634-644. doi: 10.1007/s13197-011-0559

Pingali, P. L. (ed.). (2001). "CIMMYT 1999/2000 World maize facts and trends," in Meeting World Maize Needs: Technological Opportunities and Priorities for the work. TS, TD, NC, and VS conducted biochemical and genotype analyses. SN, NC, and SC analyzed the data. NC, KA, and SN contributed to the manuscript preparation.

\section{FUNDING}

Financial support of the Department of Biotechnology (DBT), Government of India (GOI) through the project entitled Marker-assisted introgression of $L y c E$ gene for enhanced ProA in maize (BCIL/NER-BPMC/2011/1058 dt. 20.12.2011 of BCIL, New Delhi) is acknowledged. The funder had no role in the work design, data collection, and analysis, or decision and preparation of the manuscript.

Public Sector (Mexico: CIMMYT, International Maize and Wheat Improvement Center), 60.

Prasanna, B. M. (2010). Diversity in global maize germplasm: characterization and utilization. J. Biosci. 37, 843-855. doi: 10.1007/s12038-012-9227-1

Prasanna, B. M., Pixley, K., and Warburton, M. L., Xiao-Xie, C. (2010). Molecular marker-assisted breeding options for maize improvement in Asia. Mol. Breeding 26, 339-356. doi: 10.1007/s11032-009-9387-3

Ragot, M., and Lee, M. (2007). "Marker-assisted selection in maize: current status, potential, limitations and perspectives from the private and public sectors," in Marker-Assisted Selection-Current Status and Future Perspectives in Crops, Livestock, Forestry and Fish (Rome: FAO), 117-150.

Rodriguez-Amaya, D. B., and Kimura, M. (2004). HarvestPlus Handbook for Carotenoid Analysis. Washington, DC: International Food Policy Research Institute (IFPRI).

Selvi, D. T., Senthil, N., Yuvaraj, A., John Joel, A., Mahalingam, A., Nagarajan, P., et al. (2014). Assessment of crtRB1 polymorphism associated with increased $\beta$-carotene content in maize (Zea mays L.) Seeds. Food Biotechnol. 28, 41-49. doi: 10.1080/08905436.2013.870077

Sharma, L., Prasanna, B. M., and Ramesh, B. (2010). Analysis of phenotypic and microsatellite-based diversity of maize landraces in India, especially from the North East Himalayan region. Genetica 138, 619-631. doi: 10.1007/s10709-010-9436-1

Vignesh, M., Hossain, F., Nepolean, T., Saha, S., Agrawal, P. K., Guleria, S. K., et al. (2012). Genetic variability for $\operatorname{kernel} \beta$-carotene and utilizationof $\operatorname{crtRB} 1$ 3'TE gene for biofortification in maize (Zea mays L.). Indian J. Genet. 72, 189-194.

West, K. P. Jr. (2003). Vitamin A deficiency disorders in children and women. Food Nutr. Bull. 24, S78-90. doi: 10.1177/15648265030244S204

Yan, J., Kandianis, C. B., Harjes, C. E., Bai, L., Kim, E., Yang, X., et al. (2010). Rare genetic variation at Zea mays crtRB1 increases $\beta$-carotene in maize grain. Nat. Genet. 42, 322-327. doi: 10.1038/ng.551

Zunjare, R. U., Hossain, F., Muthusamy, V., Baveja, A., Chauhan, H. S., Bhat, J. S., et al. (2018). Development of biofortified maize hybrids through marker-assisted stacking of $\beta$-carotene hydroxylase, lycopene- $\varepsilon$ cyclase and opaque2 genes. Front. Plant Sci. 9:178. doi: 10.3389/fpls.2018. 00178

Conflict of Interest: The authors declare that the research was conducted in the absence of any commercial or financial relationships that could be construed as a potential conflict of interest.

Copyright (C) 2020 Natesan, Singh, Duraisamy, Chandrasekharan, Chandran, Adhimoolam, Muniyandi, Sampathrajan, Kalipatty Nalliappan, Muthurajan and Meitei. This is an open-access article distributed under the terms of the Creative Commons Attribution License (CC BY). The use, distribution or reproduction in other forums is permitted, provided the original author(s) and the copyright owner(s) are credited and that the original publication in this journal is cited, in accordance with accepted academic practice. No use, distribution or reproduction is permitted which does not comply with these terms. 